\title{
Front Matter: Volume 10882
}

, "Front Matter: Volume 10882," Proc. SPIE 10882, Multiphoton Microscopy in the Biomedical Sciences XIX, 1088201 (23 May 2019); doi:

$10.1117 / 12.2523414$

SPIE. Event: SPIE BiOS, 2019, San Francisco, California, United States 


\title{
PROGRESS IN BIOMEDICAL OPTICS AND IMAGING
}

\section{Multiphoton Microscopy in the Biomedical Sciences XIX}

\author{
Ammasi Periasamy \\ Peter T. C. So \\ Karsten König \\ Editors
}

3-6 February 2019

San Francisco, California, United States

Sponsored by

SPIE

Cosponsored by

Becker \& Hickl GmbH (Germany) • Carl Zeiss (United States) • JenLab GmbH (Germany) • Chroma Technology Corporation (United States) - Leica Microsystems (United States) - Spectra-Physics, a division of MKS Instruments (United States) • Coherent Inc. (United States) • Applied Scientific Instrumentation (United States) • Semrock Inc. (United States) • PicoQuant Photonics

(United States) • ISS, Inc. (United States) • Excelitas Technologies

Published by

SPIE

\section{Volume 10882}


The papers in this volume were part of the technical conference cited on the cover and title page. Papers were selected and subject to review by the editors and conference program committee. Some conference presentations may not be available for publication. Additional papers and presentation recordings may be available online in the SPIE Digital Library at SPIEDigitalLibrary.org.

The papers reflect the work and thoughts of the authors and are published herein as submitted. The publisher is not responsible for the validity of the information or for any outcomes resulting from reliance thereon.

Please use the following format to cite material from these proceedings:

Author(s), "Title of Paper," in Multiphoton Microscopy in the Biomedical Sciences XIX, edited by Ammasi Periasamy, Peter T. C. So, Karsten König, Proceedings of SPIE Vol. 10882 (SPIE, Bellingham, WA, 2019) Seven-digit Article CID Number.

ISSN: 1605-7422

ISSN: 2410-9045 (electronic)

ISBN: 9781510624061

ISBN: 9781510624078 (electronic)

Published by

SPIE

P.O. Box 10, Bellingham, Washington 98227-0010 USA

Telephone +1 3606763290 (Pacific Time) · Fax +1 3606471445

SPIE.org

Copyright (C) 2019, Society of Photo-Optical Instrumentation Engineers.

Copying of material in this book for internal or personal use, or for the internal or personal use of specific clients, beyond the fair use provisions granted by the U.S. Copyright Law is authorized by SPIE subject to payment of copying fees. The Transactional Reporting Service base fee for this volume is $\$ 18.00$ per article (or portion thereof), which should be paid directly to the Copyright Clearance Center (CCC), 222 Rosewood Drive, Danvers, MA 01923. Payment may also be made electronically through CCC Online at copyright.com. Other copying for republication, resale, advertising or promotion, or any form of systematic or multiple reproduction of any material in this book is prohibited except with permission in writing from the publisher. The CCC fee code is $1605-$ $7422 / 19 / \$ 18.00$.

Printed in the United States of America by Curran Associates, Inc., under license from SPIE.

Publication of record for individual papers is online in the SPIE Digital Library.

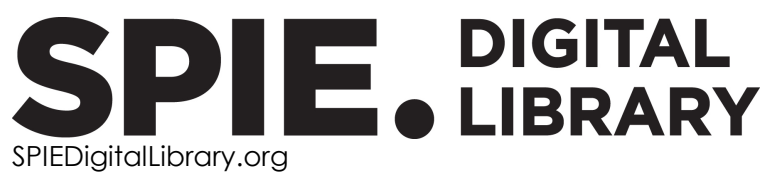

Paper Numbering: Proceedings of SPIE follow an e-First publication model. A unique citation identifier (CID) number is assigned to each article at the time of publication. Utilization of CIDs allows articles to be fully citable as soon as they are published online, and connects the same identifier to all online and print versions of the publication. SPIE uses a seven-digit CID article numbering system structured as follows:

- The first five digits correspond to the SPIE volume number.

- The last two digits indicate publication order within the volume using a Base 36 numbering system employing both numerals and letters. These two-number sets start with $00,01,02,03,04$, 05, 06, 07, 08, 09, 0A, OB ... 0Z, followed by 10-1Z, 20-2Z, etc. The CID Number appears on each page of the manuscript. 


\title{
Contents
}

\author{
vii Authors \\ xi Conference Committee \\ $\mathrm{xV}$ Introduction
}

METABOLISM/NADH/FAD/TRYPTOPHAN I

$1088206 \quad$ Fast-acquisition TCSPC FLIM with sub-25-ps IRF width (Invited Paper) [10882-5]

$1088207 \quad$ Multiparametric luminescence lifetime imaging: a new diagnostic tool to follow up bioenergetic alterations during PDT (Invited Paper) [10882-6]

METABOLISM/NADH/FAD/TRYPTOPHAN II

1088209 Interrogation of glioma metabolism on macroscale by FLIM (Invited Paper) [10882-8]

10882 OA Multiphoton FLIM imaging of NADH and FAD to analyze cellular metabolic activity of reconstructed human skin in response to UVA light [10882-9]

10882 OB Metabolic imaging by simultaneous FLIM of NAD(P)H and FAD [10882-10]

10882 OC Effects of pH on FAD autofluorescence lifetimes [10882-11]

FLIM/FRET/FCS I

10882 OF Subsurface photoluminescence lifetime imaging of photovoltaic materials using multiphoton tomography (Invited Paper) [10882-14]

10882 OG Multiphoton imaging and OCT MA for diagnosis of human melanocytic lesions (Invited Paper) [10882-15]

FLIM/FRET/FCS II

10882 Ol The SPLIT approach for enhancing the spatial resolution in pulsed STED microscopy with FastFLIM and phasor plots (Invited Paper) [10882-17] 
FLIM/FRET/FCS III

$1088200 \quad$ Genetically encoded FRET probes for direct mapping and quantification of intracellular oxygenation level via fluorescence lifetime imaging (Invited Paper) [10882-93]

\section{TECHNOLOGY DEVELOPMENT I}

10882 OS Freely tunable spectral detection for multiphoton microscopy [10882-27]

10882 OU 920-nm fiber laser delivering 100-fs pulses for nonlinear microscopy [10882-29]

\section{FLIM/FRET/FCS IV}

10882 OW Ligand-induced oligomerization of the human GPCR neurotensin receptor 1 monitored in living HEK293T cells (Invited Paper) [10882-31]

10882 OY Fluorescence lifetime imaging with a single-photon SPAD array using long overlapping gates: an experimental and theoretical study [10882-33]

$1088210 \quad$ Fluorescence lifetime imaging for viscosity and diffusion measurements [10882-105]

\section{SECOND/THIRD HARMONIC GENERATION MICROSCOPY I}

$1088212 \quad$ Fast Fourier transform second harmonic generation microscopy for probing the 3D structure of corneal lamella [10882-36]

1088213 Cardiac applications of second harmonic generation (SHG) microscopy [10882-37]

\section{SECOND/THIRD HARMONIC GENERATION MICROSCOPY II}

1088217 Connecting Mueller and Jones tensors for describing nonlinear optical conversion of unpolarized light [10882-41]

1088218 Exploratory investigation of the spatial relationships of collagen and nerves in subcutaneous white adipose tissue (scWAT) using 2-photon microscopy [10882-42] 
$108821 \mathrm{~A} \quad$ Multimodal multiphoton tomograph using a compact femtosecond fiber laser (Invited Paper) [10882-43]

10882 1B In vivo multiphoton dynamic imaging of the hepatobiliary metabolism in chronic hepatic diseases [10882-44]

\section{TECHNOLOGY DEVELOPMENT II}

$108821 G \quad$ Wide-field multiphoton imaging with TRAFIX [10882-49]

$10882 \mathrm{lJ} \quad$ Enhancement of performance in time-domain FLIM with GaAsP hybrid detectors [10882-52]

NONLINEAR AND LINEAR CHEMICAL IMAGING I

10882 1P Label-free volumetric quantitative imaging of human osteosarcoma cells by hyperspectral coherent anti-Stokes Raman scattering [10882-58]

\section{POSTER SESSION}

10882 2A Global analysis and Decay Associated Images (DAI) derived from Fluorescence Lifetime Imaging Microscopy (FLIM) [10882-23]

10882 2B Deep learning spectroscopic stimulated Raman scattering microscopy (JenLab Young Investigator Award Runner-Up) [10882-79]

10882 2C Hybrid 2-color/3-color background-free broadband CARS with passive polarization optics [10882-80]

10882 2D Pre-resonance stimulated Raman scattering spectroscopy and imaging of membrane potential using near-infrared rhodopsins (Student Poster Session Award) [10882-81]

10882 2E SRS image cytometry for high-content single cell analysis [10882-82]

10882 2F Virtual H\&E histology by fiber-based picosecond two-photon microscopy (Student Poster Session Award) [10882-83]

10882 2G Simultaneous two-photon and three-photon microscopy imaging with a dual-wavelength Er-doped fiber laser [10882-84]

$108822 \mathrm{H} \quad$ Three-dimensional deep tissue multiphoton frequency-domain fluorescence lifetime imaging microscopy via phase multiplexing and adaptive optics (JenLab Young Investigator Award Winner) [10882-86] 
$1088221 \quad$ Comparison of emission wavelengths for in vivo deep imaging of mouse brain [10882-87]

$10882 \mathrm{~J} \quad$ Multimodal microscopy toolkit for visualizing multicomponent topical drug formulations in humans (Student Poster Session Award) [10882-88]

10882 2K Multiphoton microscopy and fluorescence lifetime imaging of the rat and patient liver with cirrhosis ex vivo [10882-90]

$10882 \mathrm{~L} \quad$ Nondestructive method for chondrocyte viability assessment in articular cartilage tissues with nonlinear optical microscopy [10882-91]

$108822 \mathrm{P} \quad$ Single-objective multiphoton light-sheet microscopy for tumor organoid screening [10882-97]

$1088225 \quad$ Nanometer-scale colocalization microscopy of Streptococcus pneumoniae filaments [10882-100]

$108822 Z$ pbICS microscopy technique for determining oligomeric state [10882-108]

1088230 Development of an electrothermal MEMS mirror based two-photon microscopy probe [10882-109]

$1088231 \quad$ Near-infrared molecular fieldoscopy of water [10882-110]

1088234 VistaVision toolbox for quantitative multi-parameter analysis of single molecule dynamics [10882-113]

1088235 Differentiation of collagens I, II, and III by second order susceptibility imaging [10882-114] 


\section{Authors}

Numbers in the index correspond to the last two digits of the seven-digit citation identifier (CID) article numbering system used in Proceedings of SPIE. The first five digits reflect the volume number. Base 36 numbering is employed for the last two digits and indicates the order of articles within the volume. Numbers start with 00, 01, 02, 03, 04, 05, 06, 07, 08, 09, OA, OB...0Z, followed by 10-1Z, 20-2Z, etc.

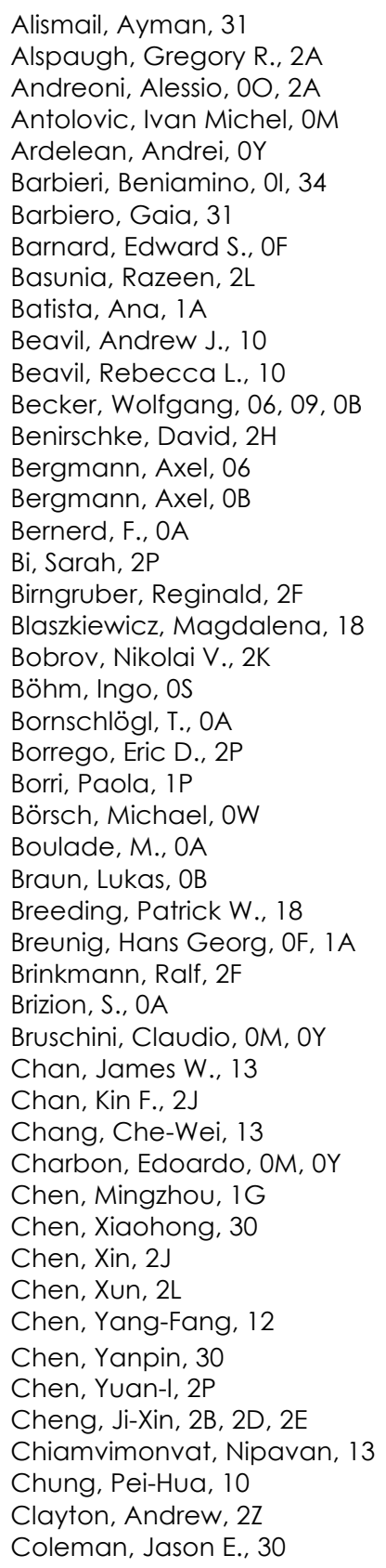

Cornell, Bethan, 10

Coskun, Ulas C., 34

Crnjar, Alessandro, 10

Davydova, Diana, 0G

DeGrip, Willem J., 2D

Deng, Fengyuan, 2B

Dholakia, Kishan, 1G

Diaspro, Alberto, 01

Ding, Changqin, 17

Dong, Chen-Yuan, 12, 1B, 35

Draxinger, Wolfgang, $2 \mathrm{~F}$

Dreiss, Cécile A., 10

Dudenkova, Varvara V., 09, 0G, 2K

Economou, Augoustina M., 10

Eibl, Matthias, $2 \mathrm{~F}$

Elagin, Vadim, OG

Errington, Rachel, 1P

Escobet-Montalbán, Adrià, $1 G$

Evans, Conor L., 2J

Fast, Alexander, 2J

Fattahi, Hanieh, 31

Fedoseeva, Vera V, 09

Friedenaver, Axel, OU

Galey, J.-B., OA

Gannon, Steven, 2L

Garanina, Oksana, OG

Gottschall, Thomas, 2F

Greisberger, Isabel, OU

Gubarkova, Ekatarina, OG

Gugel, Hilmar, OS

Guldner, Ian H., 2H

Hakert, Hubertus, 2F

Han, Won Sub, $1 \mathrm{~J}$

Hao, Yunqi, 30

Harling, Mitchell, 2A

Heitkamp, Thomas, OW

Hellerer, Thomas, OU, $2 \mathrm{~S}$

Hermsmeier, Maiko, 2J

Hilleringmann, Markus, $2 S$

Hirvonen, Liisa M., 10

Hovhannisyan, Vladimir A., 1B

Howard, Scott S., 2H

Hsueh, Chiu-Mei, 35

Huang, Hsu-Cheng, 1B

Huang, Kai-Chih, 2D, 2E

Huang, Lin, 2G

Huang, Shao-Po, 2P

Huang, Yao-De, 1B, 35

Huber, Robert, 2F 
Hussain, Syed Ali, 31

Hwang, Wonsang, $1 \mathrm{~J}$ Ishitsuka, Yuji, OI

James, Arjuna L., 10

Jeong, Sinyoung, 2J

Kalinina, Sviatlana, 07, 32

Kang, Mingu, $1 \mathrm{~J}$

Kao, Hillary K. J., 13

Karpf, Sebastian Nino, 2F

Karuna, Arnica, 1P

Kavanagh, Thomas, 2C

Khalil, Andre, 18

Kim, Dongeun, $1 \mathrm{~J}$

Kim, Dug Young, 1 J

Kim, Minsu, 2l

Kiselev, Nikolai M., 2K

Kisileva, Elena B., 09

Klemenova, Irina, OG

Knutson, Jay R., 00, 2A

Kolb, Jan Philip, 2F

König, Aisada, 1A

König, Karsten, OF, IA

Krausz, Ferenc, 31

Kuo, Yu-An, 2P

Kuznetsova, Daria S., 2K

Lajevardipour, Alireza, $2 Z$

Langbein, Wolfgang, IP

Lanzanò, Luca, Ol

Le Marois, Alix, 10

Ledford, Hannah A., 13

Lee, Hsuan-Shu, 1B, 35

Lee, Hyeon Jeong, 2D

Lee, Sang Yoon, $1 \mathrm{~J}$

Lee, Sheng-Lin, 12, 1B, 35

Levitt, James A., 10

Li, Junjie, 2E

Li, Yang, 2 L

Liao, Shih-Chu (Jeff), 34

Lieu, Deborah K., 13

Limpert, Jens, 2F

Lin, Chih-Ju, 1B

Lin, Haonan, $2 B$

Littleton, Brad, 2C

Liu, Yen-Liang, 2P

Lorenz, Christian D., 10

Lukina, Maria, 09

Mamaeva, Natalia, 2D

Masia, Francesco, IP

Mei, Gaoxiang, 2D

Meyer, Tobias, $2 \mathrm{~F}$

Michalet, Xavier, OM, OY

Mohseni, Mojtaba, $2 S$

Molteni, Carla, 10

Moon, Sucbei, $1 \mathrm{~J}$

Mrowka, Ralf, OW

Müller, Philippe-Fabian, OB

Murphy, Michael, 2A

Nadeau, Elizabeth, 2L

Nedbal, Jakub, 10

Ness, Stefan, 25
Neugart, Felix, OS

Nguyen, Trung D., 2P

Nichols, Evan L., $2 \mathrm{H}$

Nie, Yu, 2C

Orlinskaya, Natalia, $0 \mathrm{G}$

Ortiz-Zapater, Elena, 10

Parsons, Maddy, 10

Pellegrini, Vincent, 2L

Pena, A.-M., OA

Penjweini, Rozhin, 00, 2A

Planel, E., OA

Polzer, Christoph, OU, 2S

Popp, Jürgen, 2F

Rädler, Joachim, $2 S$

Reeß, K., 07

Reeves, Russell, $2 \mathrm{~L}$

Reuter, Stefanie, OW

Richards, David, 2C

Roarke, Branden, 00

Rodimova, Svetlana A., 2K

Rothschild, Kenneth J., 2D

Rück, Angelika, 07, 32

Sackett, Dan L., 00

Saini, Neal, 2L

Schaefer, Patrick, 32

Schmitz, Rebecca, OC

Schweinberger, Wolfgang, 31

Selvin, Paul R., Ol

Shah, Priyank, 2C

Shah, Sunil, Ol, 34

Shcheslavskiy, Vladislav I., 09

Shirmanova, Marina V., 09

Shlivko, Irena, OG

Sielaff, Hendrik, OW

Simpson, Garth J., 17

Skala, Melissa C., OC

Skrobol, Christoph, OU

Smietana, Stefan, 06

Smirnov, Aleksander V., $2 \mathrm{~A}$

Smith, Cody J., $2 \mathrm{H}$

Steinmark, I. Emilie, 10

Strub, Marie-Paule, 00, 2A

Sturzenbaum, Stephen, 2C

Suarez Ibarrola, Rodrigo, OB

Suhling, Klaus, 10

Sun, Yuansheng, 01,34

Tang, Shuo, 2G

Teijeiro-Gonzalez, Yurema, 10

Teng, Kai-Wen, 0 I

Tilbury, Karissa B., 18

Tissot, N., OA

Tortarolo, Giorgio, ol

Townsend, Kristy, 18

Ulcickas, James R. W., 17

Ulku, Arin Can, OM, OY

Ursprung, Benedikt, OF

Vicidomini, Giuseppe, 0 I

von Einem, Bjorn, 07, 32

Walsh, Alex J., OC

Walsh, Christine, $0 \mathrm{C}$ 
Wang, Haochuan, 31

Wang, Mengran, 2 I

Wang, Wei-Hsiang, 1B

Watkins, Beckham, 2L

Weiss, Shimon, OM

Weng, Daniel, 2F

Westphal, Anika, OW

Wijesinghe, Philip, $1 G$

Wiltshire, Marie, $1 \mathrm{P}$

Wolfring, Bernhard, oU

Won, Youngjae, $1 \mathrm{~J}$

Xia, Fei, 21

Xie, Huikai, 30

Xu, Chris, 21

Yahioglu, Gokhan, 10

Yamamoto, Akira, 2J

Yao, Hai, 2L

Ye, Tong, $2 \mathrm{~L}$

Yeh, Hsin-Chin, 2P

Zagainov, Vladimir E., 2K

Zagaynova, Elena V., 09, 0G, 2K

Zhang, Chi, 2B, 2E

Zhang, Siyuan, $2 \mathrm{H}$

Zhang, Xiao-Dong, 13

Zhang, Yide, $2 \mathrm{H}$

Zhou, Liang, 30

Zong, Cheng, 2B

Proc. of SPIE Vol. $108821088201-9$

Downloaded From: https://www.spiedigitallibrary.org/conference-proceedings-of-spie on 26 Apr 2023 Terms of Use: https://www.spiedigitallibrary.org/terms-of-use 
Proc. of SPIE Vol. 10882 1088201-10

Downloaded From: https://www.spiedigitallibrary.org/conference-proceedings-of-spie on 26 Apr 2023 Terms of Use: https://www.spiedigitallibrary.org/terms-of-use 


\section{Conference Committee}

Symposium Chairs

James G. Fujimoto, Massachusetts Institute of Technology (United States)

R. Rox Anderson, Wellman Center for Photomedicine, Massachusetts General Hospital (United States) and Harvard Medical School (United States)

Symposium Co-chairs:

Jennifer K. Barton, The University of Arizona (United States)

Wolfgang Drexler, Medical University of Vienna (Austria)

Program Track Chairs

Ammasi Periasamy, University of Virginia (United States)

Daniel L. Farkas, University of Southern California (United States) and SMI (United States)

Conference Chairs

Ammasi Periasamy, University of Virginia (United States)

Peter T. C. So, Massachusetts Institute of Technology (United States)

Karsten König, JenLab GmbH (Germany)

Conference Program Committee

Holly Aaron, University of California, Berkeley (United States)

Margarida Barroso, Albany Medical College (United States)

Wolfgang Becker, Becker \& Hickl GmbH (Germany)

Alberto Diaspro, Istituto Italiano di Tecnologia (Italy)

Chen-Yuan Dong, National Taiwan University (Taiwan)

Paul J. Campagnola, University of Wisconsin-Madison (United States)

Ji-Xin Cheng, Purdue University (United States)

Kevin W. Eliceiri, University of Wisconsin-Madison (United States)

Scott Fraser, The University of Southern California (United States)

Paul M. W. French, Imperial College London (United Kingdom)

Katsumasa Fujita, Osaka University (Japan)

Enrico Gratton, University of California, Irvine (United States)

Min Gu, RMIT University (Australia)

Stefan W. Hell, Max-Planck-Institut für Biophysikalische Chemie (Germany)

Fu-Jen Kao, National Yang-Ming University (Taiwan) 
Arnd K. Krueger, Newport Spectra-Physics GmbH (Germany)

Darryl McCoy, Coherent Scotland Ltd. (United Kingdom)

Wei Min, Columbia University (United States)

Junle Qu, Shenzhen University (China)

Angelika C. Rueck, Universität Ulm (Germany)

Yuansheng Sun, ISS, Inc. (United States)

Steven S. Vogel, National Institutes of Health (United States)

Xiaoliang S. Xie, Harvard University (United States) and Peking University (China)

Chris Xu, Cornell University (United States)

Elena V. Zagaynova, Privolzhsky Research Medical University (Russian Federation) and Nizhny Novgorod State Medical Academy (Russian Federation)

Bernhard Zimmermann, Carl Zeiss Jena GmbH (Germany)

Session Chairs

1 Keynote Session

Peter T. C. So, Massachusetts Institute of Technology (United States)

2 Metabolism/NADH/FAD/Tryptophan I

Elena V. Zagaynova, Privolzhsky Research Medical University (Russian Federation) and Nizhny Novgorod State Medical Academy (Russian Federation)

4 Metabolism/NADH/FAD/Tryptophan II

Angelika C. Rueck, Universität Ulm (Germany)

5 FLIM/FRET/FCS I

Steven S. Vogel, National Institutes of Health (United States)

7 FLIM/FRET/FCS II

Margarida Barroso, Albany Medical College (United States)

8 FLIM/FRET/FCS III

Beniamino B. Barbieri, ISS, Inc. (United States)

9 Technology Development I

Kevin W. Eliceiri, University of Wisconsin-Madison (United States)

10 FLIM/FRET/FCS IV

Wolfgang Becker, Becker \& Hickl GmbH (Germany)

11 Second/Third Harmonic Generation Microscopy I

Chen-Yuan Dong, National Taiwan University (Taiwan) 
12 Second/Third Harmonic Generation Microscopy II

Paul J. Campagnola, University of Wisconsin-Madison (United States)

13 In Vivo/Intravital Imaging

Vladislav I. Shcheslavskiy, Becker \& Hickl GmbH (Germany)

14 Technology Development II

Karsten König, JenLab GmbH (Germany)

15 Nonlinear and Linear Chemical Imaging I

Ji-Xin Cheng, Boston University (United States)

16 Nonlinear and Linear Chemical Imaging II

Shuhua Yue, Beihang University (China)

17 Nonlinear and Linear Chemical Imaging III

Lingyan Shi, Columbia University (United States)

18 Nonlinear and Linear Chemical Imaging IV

Eric O. Potma, University of California, Irvine (United States)

Poster Session

Holly Aaron, University of California, Berkeley (United States)

Michael Börsch, Universitätsklinikum Jena (Germany)

Alberto Diaspro, Istituto Italiano di Tecnologia (Italy)

Kevin W. Eliceiri, University of Wisconsin-Madison (United States)

Lingyan Shi, Columbia Univ. (United States) 
Proc. of SPIE Vol. 10882 1088201-14 Downloaded From: https://www.spiedigitallibrary.org/conference-proceedings-of-spie on 26 Apr 2023
Terms of Use: https://www.spiedigitallibrary.org/terms-of-use 


\section{Introduction}

Multiphoton microscopy has been established as the 3D imaging method of choice for studying living biomedical specimens from single cells and whole animals to patients with submicron resolution. 29 years have passed since the realization of two-photon laser scanning microscopy. The ever-expanding scope of applications and the continuing instrumental innovations require a forum where new ideas can be exchanged and presented. Our conference at the SPIE BIOS2019 meeting continues to address this need.

This was the 19th year of this conference and we started our conference with four Keynote lectures from leaders in the field of metabolism:

(1) Alberto Diaspro, Istituto Italiano di Tecnologia (Italy), "Multi messenger multiphoton microscopy"

(2) Ji-Xin Cheng, Boston Univ. (United States), "Highly sensitive chemical microscopy by sensing the thermal effect of infrared absorption"

(3) Xingde Li, Johns Hopkins Univ. (United States), "Nonlinear endomicroscopy for label-free histological imaging in vivo"

(4) Ammasi Periasamy, Univ. of Virginia (United States), "FLIM, FRET and FLIRR assay for investigating the mitochondrial redox state in cancer cells."

For the 7th year, we were extremely pleased to have the JenLab Young Investigator Award, in addition to our regular poster awards. JenLab Young Investigator Award is sponsored by JenLab GmbH (Germany). The award selection committee included Drs. Arnd Krueger, Spectra Physics, a division of MKS Instruments (United States), Paul Campagnola, University of Wisconsin-Madison (United States), Conor Evans, Massachusetts General Hospital (United States), Alberto Diaspro, Istituto Italiano di Tecnologia (Italy), Holly Aaron, University of California at Berkeley (United States), and the three conference chairs (Ammasi, Karsten and Peter). The selection process reviewed seven abstracts, manuscripts and five-minute oral presentations. Two finalists were selected for 15-minute oral presentation after their five-minute oral presentation. The two finalists were:

(1) Yide Zhang, Univ. of Notre Dame (United States), "Three-dimensional deep tissue multiphoton frequency-domain fluorescence lifetime imaging microscopy via phase multiplexing and adaptive optics"

(2) Haonan Lin, Boston University (United States), "Spectroscopic stimulated Raman scattering microscopy by ultrafast delay line tuning and deep learning."

The review panel selected Dr. Yide Zhang, Univ. of Notre Dame (United States), as the winner of the JenLab Young Investigator Award 2017. The winner received a certificate and \$1500. The runner-up received $\$ 500$ award. The award was presented by Prof. Dr. Karsten König, Saarland University (Germany), and President and Founder of JenLab GmbH (Germany). 
For 19 years in a row, the conference organized poster awards for the students and postdoctoral fellows. The poster award was donated by all the conference sponsors as acknowledged at the bottom of the page. The review panelists were, Holly Aaron, University of California at Berkeley (United States), Lingyan Shi, Columbia University (United States), Michael Börsch, Universitätsklinikum Jena (Germany), and Conor Evans, Massachusetts General Hospital (United States).

The 4 poster award winners were:

(1) Hyeon Jeong Lee, Boston Univ. (United States), "Pre-resonance stimulated Raman scattering spectroscopy and imaging of membrane potential using nearinfrared rhodopsins"

(2) Alexander Fast, Massachusetts General Hospital (United States), "Multimodal microscopy toolkit for visualizing multicomponent topical drug formulations in humans"

(3) Ruofan Kao, University of Virginia (United States), "FLIM imaging of autofluorescent $\mathrm{NAD}(\mathrm{P}) \mathrm{H}$ and FAD to track metabolic changes of non-adherent leukemia cells using microfluidic trapping array"

(4) Jan Philip Kolb, Medizinisches Laserzentrum Lübeck GmbH (Germany), "Virtual H\&E histology by fiber-based picosecond two-photon microscopy."

Some of the most valuable contributions in this volume are articles written by highly experienced practitioners of multiphoton microscopy. They have enumerated the most important considerations in designing multiphoton microscopes and imaging experiments. Further, updates on the state-of-the-art commercial multiphoton microscope systems are presented. This volume also includes articles describing some recent advances in major multiphoton microscope components and applications including laser light sources, ultra-fast optics, filters, FRET, FLIM, FCS, Raman, CARS, SRS and Coherent Raman microscopy and spectroscopy, single molecule, endoscopy, In vivo/Intravital imaging, metabolism measurements including NADH, FAD, tryptophan in cells and tissues and various scientific and clinical applications.

On a personal note, the conference chairs are grateful for the participation of all authors, session chairs and acknowledge the innovation-driven manufacturers and sponsors of this conference [Applied Scientific Instruments (ASI), Becker \& Hickl, Carl Zeiss. Chroma Technology, Coherent, ISS Inc., Excelitas Technologies, JenLab, Leica Microsystems, PicoQuant, Semrock (IDEX), and Spectra Physics-a division of MKS Instruments] for their enthusiastic support in organizing this conference successfully for the last 19 years. We look forward to other exciting conferences in the future and welcome your continued participation and support.

\section{Ammasi Periasamy Peter T. C. So Karsten König}

